\title{
THE OPTIMAL TIMING OF INVESTMENT IN ENERGY CONSERVATION TECHNOLOGY
}

\author{
S. Abraham RAvid
}

July 1978

NATIONAL CENTER FOR ANALYSIS OF ENERGY SYSTEMS DEPARTMENT OF ENERGY AND ENVIRONMENT

BROOKHAVEN NATIONAL LABORATORY UPTON, NEW YORK 11973 


\section{DISCLAIMER}

This report was prepared as an account of work sponsored by an agency of the United States Government. Neither the United States Government nor any agency Thereof, nor any of their employees, makes any warranty, express or implied, or assumes any legal liability or responsibility for the accuracy, completeness, or usefulness of any information, apparatus, product, or process disclosed, or represents that its use would not infringe privately owned rights. Reference herein to any specific commercial product, process, or service by trade name, trademark, manufacturer, or otherwise does not necessarily constitute or imply its endorsement, recommendation, or favoring by the United States Government or any agency thereof. The views and opinions of authors expressed herein do not necessarily state or reflect those of the United States Government or any agency thereof. 


\section{DISCLAIMER}

Portions of this document may be illegible in electronic image products. Images are produced from the best available original document. 


\title{
THE OPTIMAL TIMING OF INVESTMENT IN ENERGY CONSERVATION TECHNOLOGY
}

\author{
S. Abraham Ravid
}

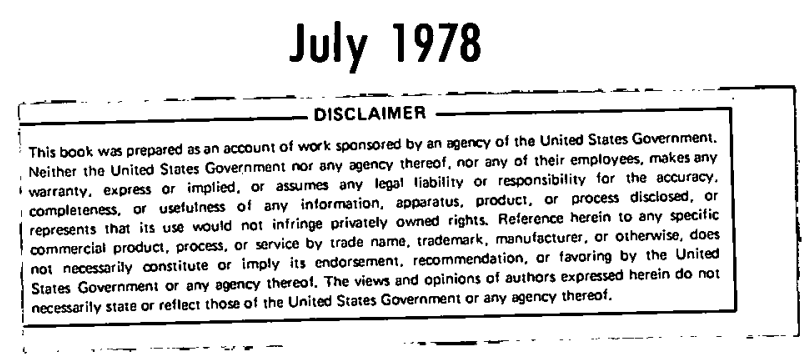

ECONOMIC AND SYSTEMS ANALYSIS DIVISION

NATIONAL CENTER FOR ANALYSIS OF ENERGY SYSTEMS

DEPARTMENT OF ENERGY AND ENVIRONMENT

BROOKHAVEN NATIONAL LABORATORY

ASSOCIATED UNIVERSITIES, INC.

UNDER CONTRACT NO. DE-AC02-76CH00016 WITH THE UNITED STATES DEPARTMENT OF ENERGY 


\section{DISCLAIMER}

This report was prepared as an acçount of work spnnsored hy an agenry of the I-Inited States Government. Neither the United States Government nor any agency thereof, nor any of their employees, nor any of their contractors, subcontractors, or their employees, makes any warranty, express or implied, or assumes any legal liability or responsibility for the accuracy, completeness, or usefulness of any information, apparatus, product, or process disclosed, or represents that its use would not infringe privately owned rights. Reference herein to any specific commercial product, process, or

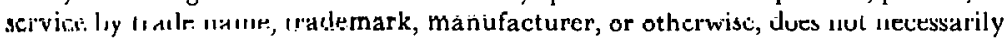
constitute or imply its endorsement, recommendation, or favoring by the United States Government or any agency, contractor or subcontractor thereof. The views and opinions of authors expressed herein do not necessarily state or reflect those of the United States frovernment or any agency, contractor or subcontractur diereuf.

Printed in the United States of America Available from

National Technical Information Service

U.S. Department of Commerce 5285 Port Royal Road Springfield, VA 22161

Price: Printed Copy $\$ 6.00$; Microfiche $\$ 3.50$ 
CONTENTS

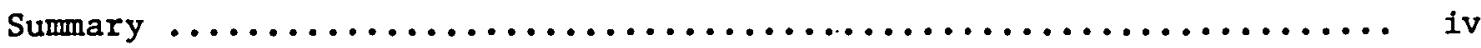

Acknowledgments $\ldots \ldots \ldots \ldots \ldots \ldots \ldots \ldots \ldots \ldots \ldots \ldots \ldots \ldots \ldots \ldots \ldots \ldots \ldots \ldots \ldots$ iv

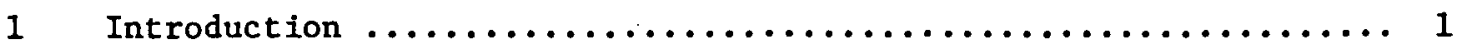

2 One-Time Improvement in Equipment Efficiency -

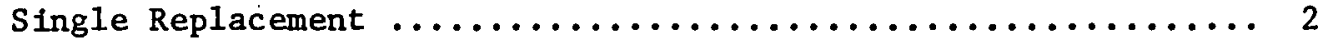

2.1 The Basic Model - Assumptions ................... 2

2.2 The Basic Model - Analysis ..................... 3

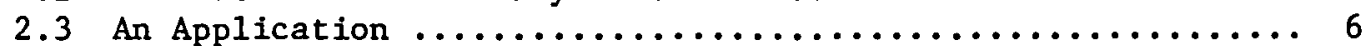

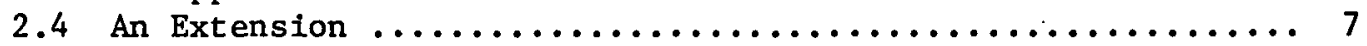

3 One-Time Improvement - Multiple Replacement $\ldots \ldots \ldots \ldots \ldots \ldots \ldots \ldots 7$

3.1 A Chain Replacement Model ....................... 7

3.2 Price Increases - A Special Case .................... 9

4 Time-Dependent Efficiency Improvement $\ldots \ldots \ldots \ldots \ldots \ldots \ldots \ldots \ldots$

4.1 The Availability of Improved Equipment Over Time ........ 11

4.2 An Implementation ............................. 12

5 Upper Limits on Research and Development $\ldots \ldots \ldots \ldots \ldots \ldots \ldots \ldots 14$ 5.1 Derivation of Upper Bounds ...................... 14

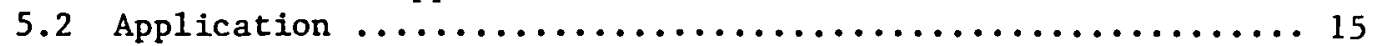

6. A Note on Continuous Replacement of Equipment $\ldots \ldots \ldots \ldots \ldots \ldots \ldots$

7 A General Dynamic Programing Formulation $\ldots \ldots \ldots \ldots \ldots \ldots \ldots 17$

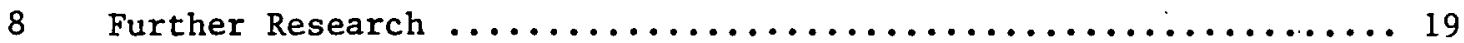

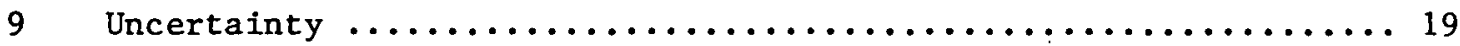

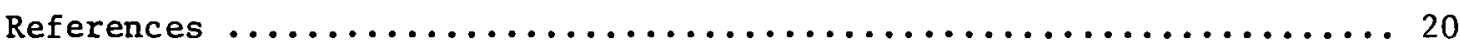

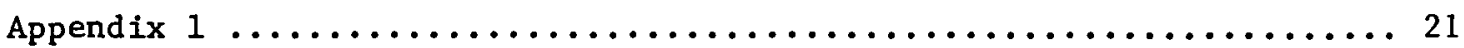

FIGURES

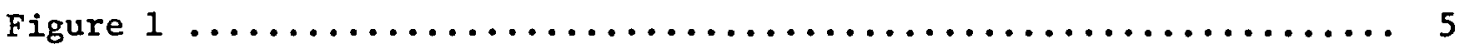




\section{SUMMARY}

It is assumed that an energy-conserving technological invention has been made. Given the cost of equipment replacement and future energy prices, optimal investment time in the new equipment is calculated. Various assumptions are made about the nature of replacement, its cost; and the equipment available, including the assumption that further technological progress will occur in the future. Replacement models as well as dynamic programming formulations are drawn upon. A major result is that replacement should take place when its marginal benefits. equal those of the alternative marginal uce of the investment funds required. Finally, an attempt is made to quantify maximum economically beneflclal development outlays for the prujecls analyzed.

\section{ACKNOWLEDGMENT}

For helpful comments and advice the author wishes to thank Professor Robert C. Lind; Professor Walter Lynn, Professor Robert Smiley; Mr. Joseph Raanan, and Mr. Av1 Vardi, of Cornell University; and Dr. William Marcuse, Dr. Jack Allentuck and Dr. Steven Carhart of Brookhaven National Laboratory. 


\section{INTRODUCTION}

This paper deals with the problem of substituting more efficient energy-consuming equipment for less efficient equipment as the more efficient alternatives become available and energy prices increase. The word equipment is used to mean anything from a simple burner to a highly complex energy end-use conversion device. The model postulates an existing piece of equipment vs a new alternative using less energy and producing the same output (though at a higher capital cost).

In the first case (Section 2), the question is whether at current energy prices it will pay to invest in the improved equipment. An attempt is made to determine whether replacement will be profitable in the future, given rising energy prices, and if so, when it should it take place. This is important because, if it is known that existing equipment will soon have to be replaced, then development and installation of the new device can be started, and long-term plans for production or consumption can include use of the optimal replacement.

In the second case it is assumed that the replacement equipment available will improve over time (as it often does) so that, even if replacement is profitable today, it may be better to wait for improvements. Calculations are made in Section 4 to determine when this is indeed so.

Given the benefit from the changes and replacement, an evaluation is made of how much one can profitably spend on research and development of the improved equipment and still do better than by keeping the old equipment.

All these questions arise often in real life decisions. The model used here is a simplification of a rather complex reality, but it provides insights into these dilemmas. Technically, replacement models are drawn upon to present a number of slightly different solutions, each under several restrictive assumptions; to derive conditions for optimal replacement in each case; and to compute upper bounds on R\&D expenses. Finally, a general formulation is developed which is less explicit than the former results but suggests a dccioion process for dealing with the general situation in which improved equipment is available and energy prices are increasing. 
A fundamental result is that equipment should be replaced at the point In time when the marginal cost savings provided by the new equipment are equal to the marginal best alternative use of the capital invested in the replacement project.

2 ONE-TIME IMPROVEMENT IN EQUIPMENT EFFICIENCY - SINGLE REPLACEMENT.

\subsection{The Basic Mode1 - Assumptions}

Consider a firm or an Individual facing a cost function with two components: (1) energy expendituro and (2) outlays relating to other inputs, assumed constant for our purposes. Such a cost function could be derived, for example, for the production of a fixed output with no substitution between energy and other inputs.

Assume that a new process becomes avallable which uses the same quantities of other inputs but less energy (an energy-augmenting technological change has taken place). Assume further that the prices of other inputs remain constant over time whereas the price of energy rises as represented by a continuous, monotonically nondecreasing function $f(t)$.

Before the mathematical discussion, these assumptions should be examined more closely. First, with reference to real prices, the price assumptions merely mean that energy price increases faster than other prices. Secondly (as shown below), the description represents accurately the case in which energy is the only variable input used (home heating, stoves and ovens, lighting, some electrical machines and appliances). The fixed quantity of other inputs in this case is obviously zero and their prices do not matter. This conclusion applies also to machines that use mainly energy and negligible amounts of nther inputs.

If the situation is generalized to a production process, an interesting piece of research by Humphrey and Moroney ${ }^{8}$ becomes relevant. Making various assumptions about the nature of production functions, and using aggregate data, these authors conclude that for a large group of products "capital and labor may be analyzed as separable from natural resource products . . ." (p. 79). In orher cases, however, they found substitutability between capital, labor, and natural resources. Although "natural resources" is a more 
general concept than one likes to use, the implication is interesting. A study by Kennedy ${ }^{9}$ shows relatively: low price elasticity of demand for most types of fossil fuel, which suggests that no ready substitutes are available. Hence, in the short run, during which changes in output and prices of other inputs are limited, an assumption of little substitution may be quite realistic. Since we do deal, however, with long time horizons, the premises of this model may not be adequate for discussing a complex production process, which is influenced by demand fluctuations and price changes of other inputs. Nevertheless, if relative prices remain the same for all inputs except energy, and for the cases mentioned above (such as those with no nonenergy inputs), this model suggests a reasonable approach for dealing with the problems discussed in Section 1.

\subsection{The Basic Model - Analysis}

Let $f(t)$ represent the price trajectory of energy inputs and let $C_{0}(f(t))$ represent the cost function of energy. It could be written less explicityly as $c_{0}(t)$. Note that, in the case of a fixed output, with no technological improvement, and in many other cases, $C_{0}(t)$ may simply be some constant multiplied by $f(t)$; but, to keep the formulation general, the energy cost function is denoted by $c_{0}(f(t))$.

Thus, the total cost function before the technological discovery is $N+C_{0}(f(t))$ where $N$ is the constant total expenditure on all inputs besides energy. After the technological change, the new, "better" cost function is $N+C_{1}(f(t))$ where $C_{1}$ is again a function of $f(t)$ such that, for all $t, C_{1}$ $(t)<C_{0}(t)$ and $C_{1}^{\prime}(t)<C_{0}^{\prime}(t) . C_{0}, C_{1}$ are assumed twice differentiable, and, since it is postulated that the only change is less energy use, in most cases $C_{1}$ can be simplified to $b C_{0}$ where $0<b<1$.

Assume that the change in technology requires an investment of $\mathrm{A}$ dollars at the time the switch is effected. (The timing of the outlay is not a restrictive assumption but a simplifying one because if costs are spread over a few periods of time, A can be regarded as the present value of the outlays, discounted back to the time of the switch).

The task is to decide with these assumptions, when to make che change in equipment. If the optimal replacement time is denoted by $T_{0}$, the end of the planning horizon by $T$ ( $T$ can be any number such that $T_{0}<T \leq \infty$ ), and the 
rate of interest by $r$ (assumed fixed and known over time), then expression (1) below denotes total cost involved in the production process, from now till the end of the horizon.

$$
\operatorname{PVTC}=\int_{0}^{T_{0}}\left[N+C_{0}(t)\right] e^{-r t} d t+\int_{T_{0}}^{T}\left[N+C_{1}(t)\right] e^{-r t} d t+A e^{-r T} 0 .
$$

Up to $T_{0}$ the (discounted) cost is calculated by the old cost function. At . $\mathrm{T}_{\mathrm{o}}$ the change is made, and from then on production proceeds by the new plucess. The last part of expression (i) denotes the cost of replacement (A) made at $T_{0}$ discounted back to the present.

The task is to find $T_{0}$ that will minimize (1), i.e., the total cost associated with the production process. To do that, the derivative of (1) with respect to ' $\mathrm{l}_{\mathrm{o}}$ is equated to zero. The resulting necessary first order condition for optimization is

$$
C_{0}\left(r_{0}\right)-C_{1}\left(T_{0}\right)=r A
$$

In the case where $c_{1}=b_{0}$ (i.e., the energy cost function decreases by a factor of $b, 0 \leq b \leq 1)$, condition (2) simplifies to

$$
(1-h) c_{n}\left(T_{n}\right)=r A \text {. }
$$

Equations (2) and (3) show that the difference between the two cost functions at time $T_{0}$ (marginal benefits if the new method is in operation at $\mathrm{T}_{\mathrm{o}}$ ) must equal the marginal opportunity cost of the funds invested in the replacement procedure $(r A)$. Since the difference between $C_{0}$ and $C_{1}$ is assumed to increase over time, at the beginning it does pay to delay the project another period at an opportunity gain of $r A-\left[C_{0}(t)-C_{1}(t)\right]$, because A dollars could produce more benefits if put to alternative uses and were not invested in replacing the old equipment. These uses are reflected in the interest rate, $r$. At $T_{0}, C_{0}\left(T_{0}\right)-C_{1}\left(T_{0}\right)=r A$, and hence one is indifferent whether A dollars are invested in equipment replacement or put to alternative uses. After $T_{o}$, if the moncy is invested in the project, it brings marginal benefits of $C_{0}(t)-C_{1}(t)$. Since this quantity is assumed to increase (though not strictly) as $t$ increases, it is larger 
than $\mathrm{rA}$, which represents the benefits from putting A dollars to the best alternative use available.

Thus $\mathrm{T}_{0}$ is the optimal switchover point.

As seen in Figure 1, the two cost functions diverge. At every point $t$ ' before $T_{0}$, the benefits, represented by the vertical difference between them, fall below the fixed opportunity cost, rA. At $\mathrm{T}_{0}$, benefits are exactly equal to the opportunity cost. At $t^{\prime \prime}$ after $T_{0}$, benefits exceed opportunity cost. The practical meaning of these results is that, although new equipment may be available that would be cheaper to operate than the old equipment, the cost of installation discourages the switch if better uses can be found for investment. funds. Later, when energy prices have increased enough, the investment becomes worthwhile.

Note that this formulation may yield a negative $T_{0}$ (as seen in the application below). By defirition, the formulation cannot accommodate such a result, but the actual meaning is simple.

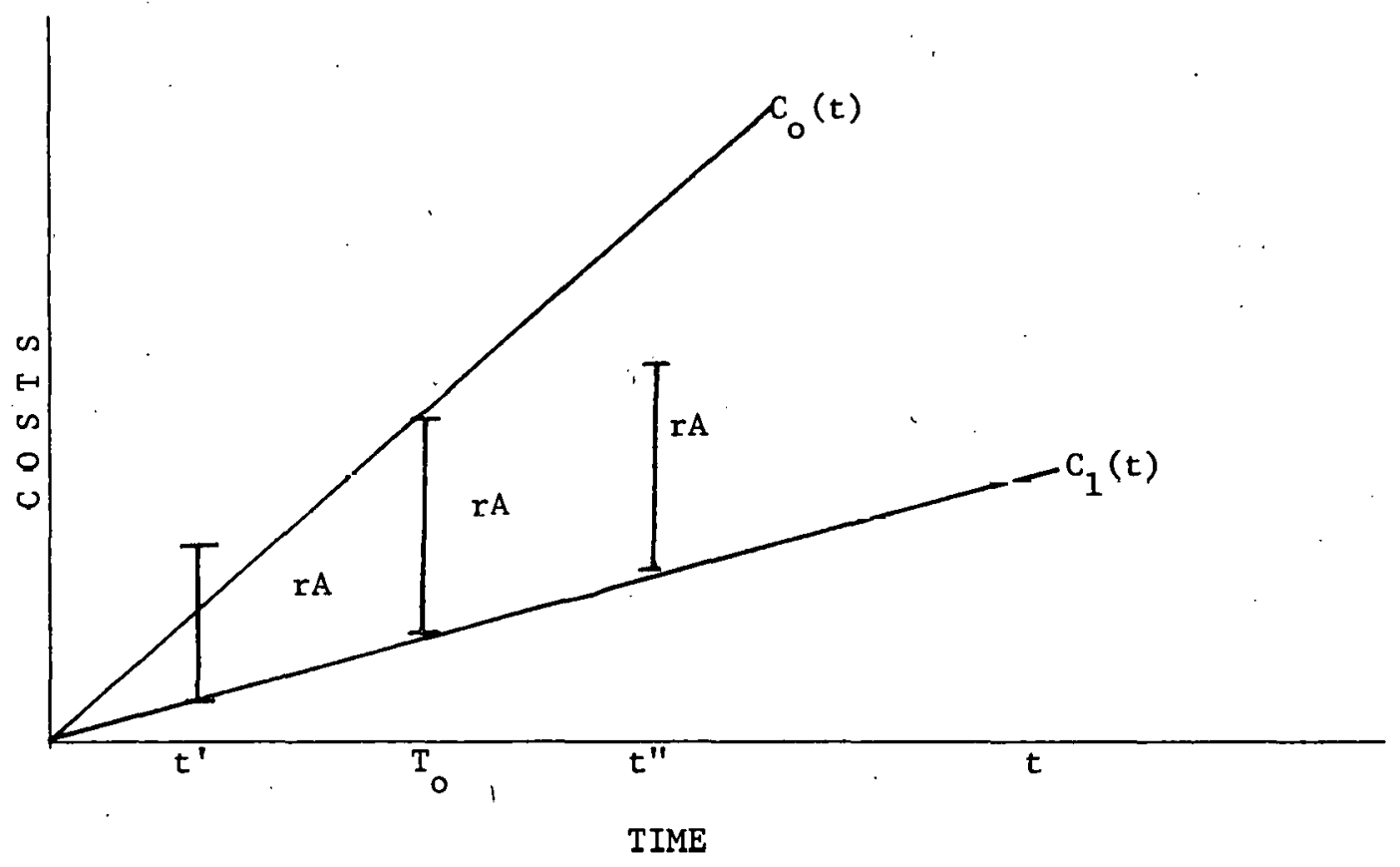

Figure 1. 
A negative $\mathrm{T}_{0}$ shows that there is no optimal positive $\mathrm{T}_{0}$, that is, at every point $t, C_{0}(t)-C_{1}(t)>$ rA. This means that replacement should have taken place earlier; in practical terms, it should be done immediately to avoid further losses.

\subsection{An Application}

This example is given to show how the optimality condition can be implemented. Let $E$ denote the amount of energy needed for producing an output by the old process. The new process requires only bE units of energy as input. The term $f(t)$ is the energy price function, and $P_{D}, b$ are constants; $0<b<1 ; P_{0}>0$.

Assume $\quad f(t)=P_{0} e^{\alpha t}$.

Thus $\quad C_{0}(t)=E P_{0} e^{\alpha t} ; \quad C_{1}(t)=b E P_{0} e^{\alpha t}$.

According to condition ( 3 )

$$
\begin{aligned}
& P_{0} E(1-b) e^{\alpha T_{0}=r A} \text { or } \quad \alpha T_{0}=\ln \left[\frac{r A}{E(1-b) P_{0}}\right] ; \\
& T_{0}=\frac{1}{\alpha} \ln \left[\frac{r A}{E(1-b) P_{0}}\right] .
\end{aligned}
$$

To illustrate this example, the data from Dacy et al. ${ }^{3}$ is used. The replacement to be considered is the fitting of houses with wall insulation. In the North Central region (Table $3,^{3} 1976$ data) wall insulation for oilheated and electrically cooled single-family houses is expected to yield an average yearly fuel savings of $\$ 118.27$ and for gas-heated and electrically. cooled houses, $\$ 68.75$. These numbers comprise $E(1-b) P_{0}$. The cost of wall insulation $(A)$ is estimated at $\$ 500$. The anticipated real annual energy price increase is $5 \%(\alpha=0.05) .4,5$ somewhat arbitrarily, the discount rate $\mathbf{r}$ is set at $0.15(15 \%): *$

Thus, for oil and electricity, $0.15 \times \$ 500=\$ 75$, and

$$
\mathrm{T}_{\mathrm{o}}=\frac{1}{0.05} \ln \left[\frac{75}{118.27}\right] \text {. }
$$

*This may be low for consumer decision making. Some observers indicate that consumers require a payback period of two years. 
The resulting number is negative; the optimum switch time has already passed, and replacement should be done immediately:*

For gas and electricity, with lower savings,

$$
\mathrm{T}_{\mathrm{o}}=\frac{1}{0.05} \ln \left[\frac{75}{68.75}\right]=1.74 \text {. }
$$

This means that wall insulation should be done 1 year and 9 months from now.

Note that a tax credit, which lowers the cost of retrofitting, will also reduce the optimal replacement time, until at $A=\$ 458.33$ (a tax credit of $\$ 41.67$ or $28 \%$ ), the optimal replacement point is $\mathrm{T}_{0}=0$, i.e., now.

\subsection{An Extension}

A first extension would be to make replacement cost (A) as well as energy cost vary over time. Usually A can be assumed to increase with time, but it may decrease with improved technology. Derivation of the optimality condition replaces Eq. (2) by

$$
C_{0}\left(T_{0}\right)-C_{1}\left(T_{0}\right)+A^{\prime}\left(T_{0}\right)=r A\left(T_{0}\right) \text {. }
$$

The interpretation is only slightly different: this time the marginal benefits from having implemented the project at time $T_{0}$ include the increase in the outlay that would have occurred during the next period (see Appendix 1 for further definitions and derivation of second-order conditions).

\section{ONE-TIME IMPROVEMENT - MULTIPLE REPLACEMENT}

\section{I A Chain Replacement Mode1}

The first model applies to the case of a one-time replacement of an old machine by a more advanced new one. The case of a simple replacement chain is discussed here, in which machines are replaced periodically as they wear out. The model used, as presented by Masse; ${ }^{1}$ Bierman, ${ }^{2}$ and others, is characterized by a few functions which are slightly modified here. $R(t)$ is the operating costs,function. For the first simple case it is assumed that energy prices are fixed through time, and therefore $R(t)$ is a function only

*This result is supported by evidence that most houses built in the North Central area have at least $11 \%$ insulation. 
of the age of the machine. $R(t)$ Includes repairs and maintenance and is assumed monotonfcally non-decreasing through time. The second function $S(t)$ is the salvage value function (assumed non-increasing over time), and $C$ is the fixed cost of a new machine of the same type. It can be shown that the optimal replacement cycle $L$ under these conditions is characterized by

$$
R(L)-S^{\prime}(L)+S(L) x-\frac{r K}{1-e^{-r L}}=0,
$$

where $r$ is the interest rate, and $K$ is the total cost of one cycle, discounted to the beginning of the cycle; expllelliy,

$$
K=\int_{0}^{L} R(t) e^{-r t} d t+c-S(L) e^{-r L} \text {. }
$$

(A similar expression for a more complex case is explicitly derived below). Now assume that a new machine is available which uses less energy and thus has a lower operating cost function $R_{1}(t)$. [lower in the sense defined in Section 2 for $C$, i.e., $R(t)>R_{1}(t) R^{\prime}(t)>R_{1}^{\prime}(t)$ for every $\left.t\right]$ but which costs more to install. say $C_{1}$. The optimal replacement cycle for this second type of machine, $\mathrm{L}_{1}$, can be characterized by an equation similar to Eq. (6).

It is assumed that after the first machine is replaced by the improved device, the new equipment will be optimally replaced again and again by the same kind ad infinitum. When is the best time to install the new equipment? The answer requires finding the optimal $T_{0}$ that will minimize the following expression:

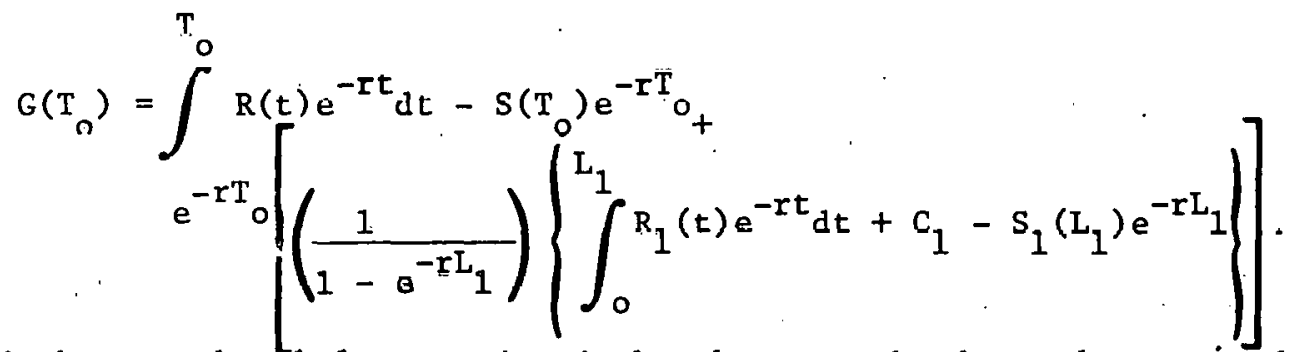

Since $L_{1}$ is known, the whole quantity in brackets can be denoted as $Q$, and it is a constant in the optimization process. Eq. (7) can be rewritten as

$$
G\left(T_{0}\right)=\int_{0}^{T} R(t) e^{-r t} d t-S\left(T_{0}\right) e^{-r T_{0}}+e^{-r T}{ }_{0} Q
$$


The first part of Eq. (7) or (8) represents the costs associated with the old equipment until $T_{0}$. The salvage value at $T_{0}$ is deducted, and the costs associated with operation of the new equipment, replaced optimally with similar equipment ad infinitum, are added. The costs of each replacement cycle are equal, but the sertes converges to $Q$ because of the discount factor.

To obtain the necessary conditions for optimality, the derivative of (8) is taken with respect to $T_{0}$ and equated to zero to obtain condition (9):

$$
R\left(T_{0}\right)-S^{\prime}\left(T_{0}\right)+r S\left(T_{0}\right)-r Q=0
$$

(The model can easily be extended to the case where $C$ is time dependent.) If $S(t)=0$ for all $t$, then Eq. (9) becomes simply

$$
R\left(T_{0}\right)=r \underline{Q} .
$$

That suggests a rather straightforward interpretation: the first machine is replaced with a better one when the operating expenses increase enough to equal the discounted cost of delaying the replacement.

Since fixed energy prices are assumed in this case, the intuitive reason for not replacing immediately with the available better equipment is that a new machine has just been bought thus it pays to use it for a while and to replace it only when its performance deteriorates to the point that the replacement investment is worth while. (Second-order conditions are detailed in Appendix 1.)

\subsection{Price Increases - A Special Case}

In this section the previous assumptions, except that of fixed energy prices, are retained. Energy prices are postulated to increase through time, but in a very special manner, namely, such that at every cycle of $L_{1}$ (the optimal replacement cycle for the better equipment) all the previous cycle's costs are multiplied by $e^{\alpha}$, where $\alpha$ is a given constant. If the cost of the first cycle is $k_{1}$, then the second cycle costs $k_{1} e^{\alpha}$, the third $k_{1} e^{2 \alpha}$, etc. Operating costs, installation costs of new equipment, and salvage value all increase by a factor of $e^{\alpha}$ during each period of $L_{1}$ years. If only the new lype of machinc io used and it is nptimally replaced, i.e., every $L_{1}$ years, then the total cost of operating discounted to the point in time when the new machine is installed is 


$$
K_{1}+K_{1} e^{\left(\alpha-r L_{1}\right)}+\ldots K_{1} e^{(i-1)\left(\alpha-r L_{1}\right)}+\ldots=K_{1}\left(\frac{1}{1-e^{\alpha-r L} L_{1}}\right) \stackrel{\text { defn. }}{=} Q
$$

Obviously an additional condition to be imposed is $\alpha-\mathrm{rL}_{1}<0$ or $\alpha / \mathrm{r}<\mathrm{L}_{1}$. For example, the assumption of $\alpha=r$ gives the reasonable restriction $L_{1}>1$. Naturally, $\mathrm{L}_{1}$ must be rederived for the price increase case. The method, however, is similar to the one used in the replacement literature to derive Eq. (6). In essence, $L_{1}$ is determined, by the condition

$$
\frac{\partial(\text { PVTC })}{\partial L_{1}}=R\left(L_{1}\right)-S^{\prime}\left(L_{1}\right)+S\left(L_{1}\right) I-\frac{K_{1}}{1-e^{-r L_{1}+\alpha}}=0 \text {. }
$$

Given this $L_{1}$, new optimal replacement conditions can be derived under the assumption that during the period in which the first type of equipment is used prices rise continuously through time; 1.e., if the replacement takes place at time $T_{0}$, the cost of the new project is $\mathrm{K}_{1}\left(e^{\alpha \mathrm{T}_{0} / L_{1}}\right)$. PVTC is thus $\exp \left[(\alpha-2) T_{0} / L_{1}\right]$. Q. It could be assumed more simply that prices do not rise at all until replacement takes place, or that they increase by $e^{\alpha}$ if replacement is not immediate, 1.e., at time point zero. However, the results will not be substantially different. The PVTC for the whole process from time 0 can now be calculated:

$$
\begin{aligned}
& \operatorname{PVTC}=\int_{0}^{T} R(t) e^{-r t} d t-S\left(T_{0}\right) e^{-r T_{0}}+e^{-r T_{0}} e^{\alpha T_{0} / L_{1}}, \\
& \dot{0}=\frac{\partial(\text { PVTC })}{\partial T_{0}}=R\left(T_{0}\right) e^{-r T}-S^{\prime}\left(T_{0}\right) e^{-r T_{0}}+r e^{-r T_{0}} S\left(T_{0}\right)+ \\
& Q\left(\frac{\alpha}{T_{1}}-\mathbf{r}\right) e^{T_{0}\left(\frac{\alpha}{L_{1}}-r\right)} \text {. }
\end{aligned}
$$

The condition for optimality is thus

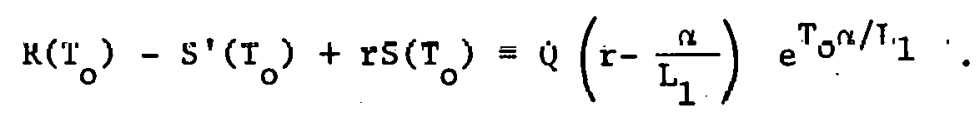

For $S(t)=0$ for ail $t$, condition (11) simplifies to

$$
R\left(T_{0}\right)=Q\left(r-\frac{\alpha}{L_{1}}\right) e^{\alpha T_{0} / L_{1}}
$$

(It has been assumed that $r>\alpha / L_{1}$; therefore, $T_{0}$ may exist. See secondorder conditions in Appendix 1.) 


\section{TIME-DEPENDENT EFFICIENCY IMPROVEMENT}

\subsection{The availability of Improved Equipment Over Time}

In this section, all the assumptions of the model presented in Section 2.1 are retained (only one replacement occurs, and if the equipment were not replaced it would last forever) but the additional assumption is made that the new and better equipment improves over time.

Formally, at calendar time $T_{0}$, the equipment can be replaced by a piece of machinery characterized by a cost function $C_{1}\left(T_{0}, t\right)$ such that for all $T_{1}<T_{0}$ and for all $t>T_{0}, C_{1}\left(T_{0}, t\right)$ is better in the sense of Section 2.1 than $C_{1}\left(T_{1}, t\right)$. Thus the following expression must be minimized with respect to $\mathrm{T}_{\mathrm{o}}$ :

$$
\int_{0}^{T}[N+C(t)] e^{-r t} d t+\int_{T_{0}}^{T}\left[N+C_{1}\left(T_{0}, t\right)\right] e^{-r t} d t+A\left(T_{0}\right) e^{-r T_{0}} .
$$

In this case $C_{1}$ is a function of both calendar time and the time of replacement. As before, no allowance is made for machine depreciation. The derivative with respect to $T_{0}$ is equated to zero to obtain

$C\left(T_{0}\right) e^{-r T_{0}}-C_{1}\left(T_{0}, T_{0}\right) e^{-r T_{0}}+\int_{T_{0}}^{T} \frac{\partial C_{1}}{\partial T_{o}} e^{-r t} d t+A^{\prime}\left(T_{0}\right) e^{-r T_{0}}-r A\left(T_{0}\right) e^{-r T_{0}}=0$ $C\left(T_{0}\right) e^{-r T_{0}}-C_{1}\left(T_{0}, T_{0}\right) e^{-r T_{0}}+A^{\prime}\left(T_{0}\right) e^{-r T} 0=r A\left(T_{0}\right) e^{-r T_{0}}-\int_{T_{0}}^{T} \frac{\partial C_{1}}{\partial T_{0}} e^{-r t} d t$.

$C$ is a function of one variable, whereas $C_{1}$ has two independent arguments. However, $C$ could be presented as $C(0, t)$ since it is assumed that the first replacement takes place at a fixed time which, with no loss of generality, could be assumed to be time zero. Note also that this solution is for the case in which A 1s r1me dependent.

The interpretation of Eq. (15) is less intuitive than in previous cases. Essentially, the left-hand side is similar to what appeared before except that all the terms are discounted to the present or initial time; it still shows the marginal loss incurred by not replacing the machine at time $T_{0}$. 
Operating costs $\left(C>C_{1}\right)$ are higher, and, assuming that A increases with time, that marginal increase, $A^{\prime}\left(T_{0}\right)$, is also absorbed. In other words, delaying the investment caused an $A^{\prime}\left(T_{0}\right)$ increase in installation costs. The right-hand side shows the marginal gain from delaying the investment. Here, $\mathrm{rA}\left(\mathrm{T}_{0}\right)$ represents the marginal profit from the best alternative use of A dollars, and

$$
\int_{T_{0}}^{T} \frac{\partial C_{1}}{\partial T_{0}}
$$

shows the total advantage in costs resulting from delaying the replacement due to the svallability of improved equipment later. Bulh quanileles are discounted back to the present, as are the terms on the left-hand side. There is a minus sign before the integral, but, since $\partial \mathrm{C}_{1} / \partial \mathrm{T}$ is negative by definition $\left(C_{1}\right.$ is decreasing over time as a function of the replacement instant), the overall result is a positive quantity.

For computational simplicity it may be more convenient to write Eq. (15) as

$$
C\left(T_{0}\right)-C_{1}\left(T_{0}, T_{0}\right)+A^{\prime}\left(T_{0}\right)=r A\left(T_{0}\right)-\left\{\int_{T_{0}}^{T} \frac{\partial C_{1}}{\partial T_{0}} e^{-r t} d t\right) e^{-r T_{0}} .
$$

(See Appendix 1 for second-order conditions for minimization.) In addition to the variation in.installation costs, which may make it desirable to wait until the increase in energy prices justifies the investment, there is another consideration, namely, that future equipment will be better. Thus, even if the cost-benefit calculation justifies immediate replacement, the switch may be delayed in order to have cheaper operation in all future periods. Recall that by definition, in this model, only one replacement is made, and thus it affects all future periods.

\subsection{All Implementicion}

In many cases the actual calculation of $T_{0}$ may be prohibitively complex, but in quite a few other cases it is possible. As an example, the application presented in Section 2.3 can be modified. Everything remains the same (note that in this simple case, $A$ is constant over time) except that $C_{1}$ becomes a function of replacement time as well, in the following manner:

$$
C_{1}\left(t, T_{0}\right)=b E P_{0} e^{\alpha t} e^{-\alpha T_{0}}
$$


Substitution in Eq. (16) yields

$$
\begin{aligned}
& E P_{0} e^{\alpha T_{0}}-E b P_{0} e^{\alpha T_{0}} e^{-\alpha T_{0}}=r A-\left\{\int_{T_{0}}^{o}(-\alpha) b E P_{0} e^{\alpha t} e^{-\alpha T_{0} e^{-r t} d t}\right\} e^{r T_{0}}, \\
& E P_{0} e^{\alpha T_{0}}-\alpha b P_{0} E=r A+\left\{\alpha b E P_{0} e^{-\alpha T_{0}} \int_{T_{0}^{\infty}}^{\infty} e^{(\alpha-r) t} d t\right\} e^{r T_{0}} .
\end{aligned}
$$

Assuming $\alpha-r<0$, i.e., $\dot{\alpha}<r$, one obtains

$$
\begin{aligned}
& E P_{0} e^{\alpha T_{0}}-b P_{0} E=r A+\left\{\alpha b E P_{0} \frac{1}{\alpha-r} e^{-\alpha T_{o_{e}}(\alpha-r) T_{o_{e}} T_{0}}\right\}, \\
& T_{0}=\frac{1}{\alpha} \ln \left[\frac{r A}{E P_{0}}-b \frac{r}{\alpha-r}\right] .
\end{aligned}
$$

The retrofitting case ${ }^{3}$ provides no accurate data about total cost. Hence, $b$ must be estimated. Assume $b=0.8$. Again $\alpha=0.05, r=0.15$, $A=\$ 500$, and thus $\mathrm{EP}_{\mathrm{O}}$ is $\$ 531.35$ in the first case (oil and electricity) and $\$ 343.75$ in the second case (gas and electricity). $T_{0}$ in the first case is

$$
\mathrm{T}_{0}=\frac{1}{0.05} \ln \left[\frac{0.15 \times 500}{591.35}-0.8 \frac{0.15}{-0.1}\right] \cong 5.65 \text {. }
$$

In other words, the availability of improved equipment over time moves the optimal $T_{o}$ much further into the future: $T_{0}$ is now 5 years and 8 months. Recall that it was negative with the assumption of constant-quality equipment.). For the second case,

$$
T_{0}=\frac{1}{0.05} \ln \left[\frac{0.15 \times 500}{343.75}-0.8 \frac{0.15}{-0.1}\right]^{\simeq} 7 \text {. }
$$

Here $T_{0}$ is increased from $<2$ years to 7 years.

Note that in these examples (because of the special functional form of r.) rheaper installation costs due to tax credit make only a marginal difference.

Even at zero costs, in this special case, $T_{0}$ will still be positive: 3 years and 7 months for both types of heating. The reason for this result 
is the availability of improved equipment later. Even if replacement:costs nothing, it may pay to wait for better equipment before replacing existing capita1 stock.

\section{UPPER LIMITS ON RESEARCH AND DEVELOPMENT}

\subsection{Derivation of Upper Bounds}

Note that in all the above models it is easy to derive an upper limit value for the discounted additional expenses besides installation which the project could carry; for example, research and development. Assume that the now toohnology io not yct available but can le iblalinel wllh proper development effort and that, once available, it will be used. Then the upper limit for $R \& D$ expenditures can be readily calculated.

This limit will be the cost difference between keeping the old equipment and replacing optimally according to the model conditions. Note that logically these expenses should not be directly related to the act of replacement, which is included in $\mathrm{A}$.

In the first model the difference between keeping the old equipment and replacing optimally is simply

$$
\int_{T_{0}}^{T}\left[\left(c_{0}(t)-c_{1}(t)\right] e^{-r t} d t-A e^{-r T_{0}}\right.
$$

where $T_{0}$ satisfies condition (2), $C_{0}\left(T_{0}\right)-C_{1}\left(T_{0}\right)=r A$, or condition (5), $C_{0}\left(T_{0}\right)-C_{1}\left(T_{0}\right)+A^{\prime}\left(T_{0}\right)=\operatorname{rA}\left(T_{0}\right)$, if $A_{1}$ is time dependent.

Expression (17) thus constitutes an upper limit to any discounted longrun or basic research costs associated with the project. For the case of improved equipment over time, the limit is

$$
\int_{T_{0}}^{T}\left[c(t)-c_{0}\left(I_{0}, \tau\right)\right] e^{-r T} d t-A\left(I_{0}\right) e^{-r T_{0}},
$$

where $T_{0}$ is determined such that condition (16) holds.

In general, the exact characteristics of the new equipment to be developed are not known. However, it is asserted in this section that, if there are sound expectations or engineering projections as to the performance, 
installation, and operating costs of the new equipment, then the amount that can be spent on research and development can be roughly evaluated.

To estimate an upper limit to all fixed costs associated with the project, simply set $A=0$ in Eqs. (17) and (18).

\subsection{Application}

For clarification, refer back to the home insulation example. From Dacy et al., ${ }^{3}$ it can be estimated that the total number of houses using gas heat and electric cooling located in the North Central region and suitable for wall insulation work is $6,427,250$. It was calculated in Section 2.3 that in this case the optimal $T_{0}$ is 1.74 years. For this theroretical discussion, it is assumed that all houses fit for insulation will indeed be insulated. Consequently, according to Eq. (17), a reasonable limit on research costs for each house (with $A=\$ 500, r=0.15$, and $\alpha=0.05$ ) will be

$$
\begin{aligned}
& \int_{1.74}^{\infty} 68.75 e^{(0.05-0.15) t} d t-500 e^{-0.15 \times 1.74} \\
& =\frac{1}{0.1} 68.75 e^{-0.1 \times 1.74}-500 e^{-0.15 \times 1.74}=\$ 192.56 .
\end{aligned}
$$

With 6,427,250 houses, a research and development budget for the area can be as large as $\$ 1.25$ billion. Since the model deals with discounted figures, actual outlays in current dollars may be even larger over the years. Note, however, the strong assumptions: that the benefits will last indefinitely, and that every house will install the measure (in addition to the assumed $\alpha$ and $r$, and to the reasonable application of the normative model, i.e., that optimal replacement will take place.) Nevertheless, this result does indicate that large amounts might profitably be spent on research in energyconserving methods.

If we assume imprnved equipment over time, the same data can be used to evaluate savings per house by substitution in eq. (18).

Total Savings $=\int_{T_{0}}^{\infty}\left[E P_{0} e^{\alpha t}-b E P_{0} e^{\alpha t-\alpha T_{0}}\right]^{-r t} d t-A\left(T_{0}\right) e^{-r T_{0}}$ 


$$
=E P_{0}\left[1-b e^{-\alpha T_{0}}\right] \int_{T_{0}}^{\infty} e^{\alpha t-r t} d t-A\left(T_{0}\right) e^{-r T} \cdot
$$

Substitution of the estimated $\mathrm{EP}_{\mathrm{o}}=\$ 343.75$ and $\mathrm{b}=0.8$ (see Section 3.2 ), where $T_{0}$ is 7 years, gives

$$
343.75\left[1-0.8 e^{-0.05 \times 7}\right] \frac{1}{0.1} e^{-0.1 \times 7}-500 e^{-0.15 \times 7}=\$ 563.71 \text {. }
$$

The total margin for research and development here is obviousiy huge, exceeding 3.6 billion dollars. Again, the example does not prove that that much can be invcoted in RaD, but it lues glve all luteresting indication of the magnitude of reasonable investment.

\section{A NOTE ON CONTINUOUS REPLACEMENT OF EQUIPMENT}

It should be pointed out that, with the assumption of continuous improvement of the quality of equipment available and no replacement costs, continuous replacement will take place and no piece of equipment will be kept for any length of time. For a somewhat more rigorous treatment of this point, assume that the improvement consists of lowering the cost function by a factor $b$, with $0<b<1$ at each replacement. Starting at any time, $t$, and available cost function $C(f(t))$, if replacement occurs at that point in time, the function at any future period $t+d t$ will be $b c(f(t+d t))$, which by definition of $b$ is lower than the cost function resulting if no replacement had taken place at $t$. Thus constant replacement will be opti-. mal.

Note that under these conditions it is easy to calculate the total optimal discounted cost of the operation (given $c, b, f$, ), which, with reasonable assumptions about the behavior of $f(t)$, is a finite number even if $T=\infty$ :

$$
T C=\int_{0}^{T} b^{t} c(t(t)) e^{-r t} d t
$$

In the discrete case it again turns out that, if improvement happens all the time and no replacement costs are present, the total cost expression will be

$$
C(f(0))+\frac{b C(f(1))}{(1+r)}+\ldots+\frac{b^{t} C(f(t))}{(1+r)^{t}}+\ldots
$$


This expression can in principle be calculated; for example, in the simplest case, if $f(t)=f$ is constant for all $t, C=E f$ ( $E$ being the amount of energy used), and $T=\infty$; then

$$
\sum_{t=0}^{\infty} \frac{b^{t} E f}{(1+r)^{t}}=\frac{E f}{1-b /(1+r)} .
$$

Although Eqs. (19) to (21) can hardly be used as such in the real world, they can be useful approximations to cases in which replacement costs are relatively small and equipment improves considerably. with time.

7 A GENERAL DYNAMIC PROGRAMMING FORMULATION

Some of the restrictive assumptions can be dropped, and a more general definition of the problem using a dynamic programming approach can be attempted. Although it cannot in general provide explicit analytical solutions, this formulation will provide some insight as to how decisions should be made at each stage. The. formulation given here follows Bellman. ${ }^{6}$ It is assumed as before that energy prices are increasing through time in a fashion described by a function $f(t)$; however, $t$ here represents a discrete time period. - Equipment can be replaced at the beginning of period $t$ at a cost $A_{t}$. The quality of equipment available improves through time so that, if $R_{T_{1}}$ is the operating costs function, given that replacement took place at time $T_{1}$, then $R_{T_{1}}$ is better than $R_{T_{0}}$ if $T_{1}>T_{0} \cdot R_{T}$ itself is a function of $f(t)$ and of the age of the equipment $(t-T)$, where $T$ is the last replacement time and $t$ is calendar time.

The states then have two variables: the tirst indicates the time the last replacement took place, and the second indicates calendar time. The general recursive formulation is then, if $g$ is the functional equation (optimal policy equation),

$$
g\left(T_{0}, t\right)=\min \left\{\begin{array}{l}
A_{t}+R_{t}(0, f(t))+a g(t, t+1) \\
R_{T_{0}}\left(t-T_{0}, f(t)\right)+a g\left(T_{0}, t+1\right)
\end{array}\right.
$$

where a is a discount factor. 
This formulation essentially describes a discrete decision process (although the periods of time can be infinitely sma11). At the beginning of each perfod $t$ one has to decide between replacing the equipment now and keepting the old machines. In the first case one incurs $A_{t}$ replacement costs and switches to a new (assumed instantaneous replacement), lower. operating cost function $R_{t}$. In the next period one continues according to the optimal policy, given that the last replacement occurred at the beginning of period $t$. The other alternative involves using the: old process for at least another pertod and then continuing according to the optimal policy, given replacement occurred at $T_{0}$, as was the case when entering period $t$.

As this is a backward optimization process (see Denardo ${ }^{7}$ ), the algorithm can be greatly simplified by assuming a finite number of relevant periods.

Start with the last perfod under consideration, assuming replacement has just been made. Denote this period by $t_{f}$. Then,

$$
g\left(t_{f}, t_{f+1}\right)=0
$$

and

$$
g\left(t_{f}, t_{f f}\right)=A_{t f}+R_{t f}\left(0, f\left(t_{f}\right)\right)
$$

If replacement occured at any time ' $I$ ' in the past, then

$$
g\left(T, T_{F}\right)=\min \left(\begin{array}{l}
R_{T}\left(t_{f}-T, f\left(t_{f}\right)\right) \\
g\left(t_{f}, t_{f}\right)
\end{array}\right) .
$$

From those relations and from Eq. (23) one can calculate the decision tree as far back as desired, and by the princtple of optimality the decision will be the best possible in each case. Thus this formulation, given that all the functions and constants are known or estimated, can help in formulating a long-range policy for equipment usage and purchase in the face of increasing energy prices. 


\section{FURTHER RESEARCH}

In this section some ideas for further studies stemming from the above work are briefly surveyed.

First, one could perform a cost-benefit analysis, given a time-variant investment and time-dependent costs and benefits functions. One could investigate the relationship between the optimal replacement time and other variables in the formulation such as the interest rates, the structure of the cost function, and the replacement outlay. This would permit evaluation of government policies aimed at influencing the optimal timing or the profitability of investment in energy-conserving equipment.* More detailed calculations could develop limits on research and development expenses under various assumptions.

The results from Section 5 can be used to develop expressions for total costs of projects involving frequent replacements. The dynamic programming formulation should be developed further.

All the above ideas can, as shown in a few examples, be used for predictions and normative calculations pertaining to the energy sector. Specifically, optimal timing of investment in actual, real-world conservation measures can be estimated. R\&D expenditures can be evaluated, government policies can be suggested, and, with the assumption of optimal replacement, future energy demands in some markets can be judged. These ideas may also help in cost-benefit analysis studies involving replacement of one type of equipment with a better one.

\section{UNCERTAINTY}

Although not discussed above, the introduction of uncertainty, if risk neutrality is assumed, will not alter most of the main conclusions. The only change will be the substitution of expected values of cost functions for the known values used in the present model.

\footnotetext{
*0ur research shows what policies can accelerate the replacement process. It is clear that the less replacement costs, the sooner it will take place.
} 
REFERENCES

1. P. Masse, Optimal Investment Decisions, Prentice Hall, New York, 1962.

2. H. Bierman, Quantitative Analysis for Business Decisions, 3rd ed., Trwin, 1968.

3. Dacy, Frazier, Lind, and Shanker, The Microeconomic Aspects in Energy Conservation, Vol II, IDA Report, 1976.

4. E.A. Hudson, and D. Jorgensen, U.S. energy policy and economic growth, Bell Journal, Autumn, 1974.

5. D. Barton, World 0i1 Price Projections, Unpub1ished, Brookhaven National Laboratory, 1977.

6. R. Bellman and S. Dreyfus, Applied Dynamic Programming, Rand Report R 352,1962 .

7. E.V. Denardo, Dynamic Programming: Theory and Applications, in preparation.

8. D.B. Humphrey and I.R. Moroney, Substitution among capital, labor, and natural resource products in American manufacturing, J. Political Economy, February 1975.

9. M. Kennedy, An economic model of the world oil market, Bell Journal, Autumn 1974 . 
In dealing with the basic model in Section 2.1, first-order optimality conditions were derived. The second-order conditions are derived here from Eqs. (1) and (2). Define

$$
\begin{aligned}
& y=\int_{0}^{T_{0}}\left[N+C_{0}(t)\right] e^{-r t} d t+\int_{T_{0}}^{T}\left[N+C_{1}(t)\right] e^{-r t} d t+A E^{-r T_{0}}, \\
& Y^{\prime} \equiv \frac{\partial C_{0}}{\partial T_{0}}, \quad Y^{\prime \prime} \equiv \frac{\partial^{2} y}{\partial T_{0}} ; \\
& C_{0}^{\prime}=\frac{\partial C_{0}}{\partial T_{0}}, . \quad C_{1}^{\prime}=\frac{\partial C_{1}}{\partial T_{0}}, \quad C_{1}^{\prime \prime}=\frac{\partial^{2} C_{1}}{\partial T_{0}^{2}} .
\end{aligned}
$$

Then

$$
y^{\prime}=C_{0}\left(T_{0}\right) e^{-r T_{0}}-C_{1}\left(T_{0}\right) e^{-r T_{0}}-r A e^{-r T_{0}}
$$

For minimization, a sufficient condition, given $y^{\prime}=0$, is $y^{\prime \prime}>0$, where

$$
y^{\prime \prime}=\left[C_{0}^{\prime}\left(T_{0}\right)-C_{1}^{\prime}\left(T_{0}\right)\right] e^{-r T_{0}}+r e^{-r T_{0}}\left[C_{1}\left(T_{0}\right)-C_{o}\left(T_{0}\right)\right]+r^{2} A e^{-r T_{0}} .
$$

The first expression is positive because it is assumed that $C_{1}{ }^{\prime}(t)<C_{0}{ }^{\prime}(t)$ for all $t$, including $T_{o}$, and $e^{-r T_{0}}$ is always positive. According to condition (2), at the extremal point $C_{1}\left(T_{0}\right)-C_{0}\left(T_{0}\right)=-r A$. Thus the last two terms of Eq. (26) simplify to $-\mathrm{r}^{2} \mathrm{Ae}^{-\mathrm{rT}_{\mathrm{O}}}+\mathrm{r}^{2} \mathrm{Ae}^{-\mathrm{rT}} \mathrm{o}=0$. Hence Eq. (26) is positive for all $C_{0}$ and $C_{1}$ that satisfy the stated assumptions, and minimization is guaranteed for all y such that $y^{\prime}=0$.

For the first extension, $A$ is time dependent. In this case again

$$
y^{\prime}=C_{0}\left(T_{0}\right) e^{-r T_{0}}-C_{1}\left(T_{0}\right) e^{-r T_{0}}+A^{\prime}\left(T_{0}\right) e^{-r T_{0}}-r A\left(T_{0}\right) e^{-r T_{0}}
$$

and Eq. (26) is thus modified to 


$$
\begin{aligned}
y^{\prime \prime}= & C_{0}^{\prime}\left(T_{0}\right) e^{-r T_{0}}-r e^{-r T_{0} C_{0}}\left(T_{0}\right)-C_{1}\left(T_{0}\right) e^{-r T_{0}}+r e^{-r T_{0}} C_{1}\left(T_{0}\right)+ \\
& r^{2} A\left(T_{0}\right) e^{-r T_{0}}-r A^{\prime}\left(T_{0}\right) e^{-r T_{0}}-r A^{\prime}\left(T_{0}\right) e^{-r T_{0}}+A^{\prime \prime}\left(T_{0}\right) e^{-r T_{0}} .
\end{aligned}
$$

Regrouping

$$
\begin{aligned}
& {\left[C_{0}^{\prime}\left(T_{0}\right)-C^{\prime}\left(T_{0}\right)\right] e^{-r T_{0}}+r e^{-r T_{0}}\left[C_{1}\left(T_{0}\right)-C_{0}\left(T_{0}\right)-A^{\prime}\left(T_{0}\right)\right]+} \\
& r^{2} A\left(T_{0}\right) e^{-r T_{0}}-i A^{\prime}\left(T_{0}\right) e^{-r T_{n}} \cdot A^{\prime \prime}\left(T_{0}\right) e^{-r T_{n}} .
\end{aligned}
$$

The first bracketed expression is positive with the assumption used, and, according to condition (5), the second bracketed expression is equal to $-r A\left(T_{0}\right)$. Then, tó derive a sufficient condition, conditions must be examined under which $\left[A^{\prime \prime}\left(T_{0}\right)-r A^{\prime}\left(T_{0}\right)\right] e^{-r T_{0}} \geq r A^{\prime}\left(T_{0}\right)$ (because always $e^{-r T_{0}} \geq 0$ ). The above statement is true for $A$, which is non-increasing over time $\left(A^{\prime} \leq 0\right.$ ) and strictly convex ( $A^{\prime \prime} \geq 0$ ) (or decreasing and convex). If $A$ is increasing over time and concave, there will never be a minimum; if $A$ is non-decreasing over time $\left(A^{\prime} \geq 0\right)$ and convex, there will be a minimum for all $T_{0}$ such that $A^{\prime \prime}\left(T_{0}\right) / A^{\prime}\left(T_{0}\right) \geq r$. [If $A$ is non-increasing and concave, $T_{0}$ is needed such that $\left.A^{\prime \prime}\left(T_{0}\right) / A^{\prime}\left(T_{0}\right) \leq r\right]$. Note that the above are sufficient but not necessary conditions for minimization, given $y^{\prime}=0$.

In the second, chatn replacement model, the situation is more complex. If

$$
y=\int_{0}^{T_{0}} R(t) e^{-r t} d t-S\left(T_{0}\right)+e^{-r T_{0}} Q
$$

then

$$
y^{\prime}=R\left(T_{0}\right) e^{-r T_{0}}-S^{\prime}\left(T_{0}\right) e^{-r T_{0}}-r S\left(T_{0}\right) e^{-r T_{0}}-r e^{-r T_{0}} Q
$$

Take the derivative again, with respect to $T_{0}$, to get

$$
y^{\prime \prime}=R^{\prime}\left(T_{0}\right) e^{-r T_{0}}-r R\left(T_{0}\right) e^{-r T_{0}}-S^{\prime \prime}\left(T_{0}\right) e^{-r T_{0}}+r S^{\prime}\left(T_{0}\right) e^{-r T_{0}}+
$$




$$
\begin{aligned}
& r S^{\prime}\left(T_{0}\right) e^{-r T_{0}}-r^{2} S\left(T_{0}\right) e^{-r T_{0}}+r^{2} e^{-r T} o_{0} \\
& =r e^{-r T_{0}}\left[R\left(T_{0}\right)-S^{\prime}\left(T_{0}\right)+r S\left(T_{0}\right)-r Q\right]+ \\
& \because \therefore T_{0}-r T_{0} \\
& R^{\prime}\left(T_{0}\right) e^{\prime \prime}\left(T_{0}\right) e^{-r T_{0}}+r S^{\prime}\left(T_{0}\right) e^{-r T_{0}} .
\end{aligned}
$$

By condition (9), $R\left(T_{0}\right)-S^{\prime}\left(T_{0}\right)+r S\left(T_{0}\right)-r Q=0$ at the extremal point. Thus

$$
y^{\prime \prime}=R^{\prime}\left(T_{0}\right) e^{-r T_{0}}-S^{\prime \prime}\left(T_{0}\right) e^{-r T_{0}}+r S^{\prime}\left(T_{0}\right) e^{-r T_{0}}
$$

Note first that if $S$ is identically zero (no salvage value), minimization is assured, since $R$ is assumed increasing through time. Many other cases are possible. Most plausibly, however, if $S^{\prime} \neq 0$ and $S^{\prime} \leq 0$ is assumed (the saivage value decreases over time), then, if $S$ is convex, ( $\left.S^{\prime \prime} \geq 0\right)$ then $-S^{\prime \prime}\left(T_{0}\right)+r S^{\prime}\left(T_{0}\right)$ is negative and should be smaller than $R^{\prime}\left(T_{0}\right)$ (in absolute value) for a minimum to exist at $\mathrm{T}_{0}$. Otherwise, if $\mathrm{S}$ is concave, $S^{\prime \prime}\left(T_{0}\right)+R^{\prime}\left(T_{0}\right)$ is a positive expression and need only be larger (in absolute value again) than $\mathrm{rS}^{\prime}\left(\mathrm{T}_{0}\right)$ to guarantee minimality.

In the case of price increases in the chain replacement model, the analysis is limited to a very special case. Only the simplest form, when $S=0$, is further analyzed.

$$
\begin{aligned}
& y=\operatorname{PVTC}=\int_{0}^{i} R(t) e^{-r t} d t+e^{-r T} e^{\alpha T} e^{\rho / L_{1}} Q \\
& Y^{\prime}=\frac{\partial P V T C}{\partial T_{0}}=R\left(T_{0}\right) e^{-r T_{0}}+\left(\frac{\alpha}{L_{1}}-r\right) e^{T_{0}}\left(\frac{\alpha}{L_{1}}-r\right) Q, \\
& y^{\prime \prime}=\frac{\partial^{2} P V T C}{\partial T_{0}^{2}}=R^{\prime}\left(T_{0}\right) e^{-r T_{0}}-r R\left(T_{0}\right) e^{-r T_{0}}+Q\left(\frac{\alpha}{L_{1}}-\underline{r}\right)^{2} e^{T_{0}\left(\alpha / L_{1}-r\right)} \text { (30) }
\end{aligned}
$$

According to condition (13), at the extreme point

$$
R\left(T_{o}\right)=Q\left(r-\frac{\alpha}{L_{1}}\right) e^{\alpha T_{0} / L_{1}^{\prime}}
$$


Thus Eq. (30) becomes

$$
y^{\prime \prime}=\left[R^{\prime}\left(T_{0}\right)-\frac{\alpha}{L_{1}} R\left(T_{0}\right)\right] e^{-r T_{0}} .
$$

The necessary condition is $R^{\prime}\left(T_{0}\right)>\frac{\alpha}{L_{1}} R\left(T_{0}\right)$. Since $R$ is assumed positive and increasing through time the condition requires

$$
\frac{R^{\prime}\left(T_{0}\right)}{R\left(T_{0}\right)}>\frac{\alpha}{L_{1}}
$$

In the last tase (3ection 4.1), second ordor conditiono turn out to be complex, and they do not easily yield meaningful insights. 